\title{
Distribution of Malocclusion Traits among Orthodontic Patients in a Tertiory Core Center of Western Nepal
}

\author{
Dr Hemant Kumar Halwai,' Dr Vanita Gautam² \\ 'Asso Prof, Dept of Orthodontics, ${ }^{2}$ Asso Prof, Dept. of Conservative Dentistry \& Endodontics \\ UCMS College of Dental Surgery, Bhairahawa, Nepal
}

Correspondence: Dr. Hemant Kumar Halwai; Email: drhemanthalway@gmail.com

\section{ABSTRACT}

Objectives: To determine the pattern of distribution of dental malocclusion in a sample of Nepalese orthodontic patients in Western Nepal.

Materials \& Method: A sample consisted of 200 study casts of patient who visited Department of Orthodontics, UCMS, Bhairahawa who had never undergone orthodontic treatment previously. The total sample size was divided into male and female groups, age was divided into 3 groups: 8-11 years, 12-17 years, and 18-36 years. All data was recorded and analyzed with SPSS software version 22.

Result: Among the total 200 casts examined; the distribution of malocclusion according to Angle's classification was: Class I malocclusion in 101 (50.5\%), Class II malocclusion in 90(45\%) sample and Class III in 9(4.5\%) samples.

Conclusion: Angle's Class I malocclusion was the most prevalent malocclusion among orthodontic patients visiting UCMS College of Dental Surgery.

Keywords: Angle's Class I, Angle's Class II, Angle's Class III, malocclusion, prevalence

\section{INTRODUCTION}

Crowded, irregular and protruding teeth have been a problem for some individual since antiquity and attempts to correct this disorder go back at least to 1000 BC. Angle's classification of malocclusion in 1890s was an important step in the development of orthodontics because it not only subdivided major types of malocclusion but also included the first clear and simple definition of normal occlusion in the natural dentition. ' According to Angle if the teeth were arranged on a smoothly curving lines of occlusion and class I molar relation existed, then normal occlusion would result. Angle's classification has four Classes i.e. Normal occlusion, Class I malocclusion, Class II malocclusion and Class III malocclusion. ${ }^{2}$

Difference in malocclusion characteristics or variation in dentofacial traits among various populations would be expected because of the difference in racial and ethnic composition. Information regarding most typical variation in dentofacial trait can be derived from studying how widely the trait is distributed i.e. prevalence and the frequency with which it is found i.e. incidence. It provides an important perspective for the practicing orthodontist when evaluating and advising potential patient regarding the desirability of the treatment. Also epidemiological data is essential in assessing the resource required for orthodontic services and can provide valuable information regarding the etiology of malocclusion.

Various epidemiological studies have been conducted worldwide to assess the prevalence of malocclusion and to describe the occlusal trait.3.4 Data from the third National Health and Nutrition Examination Survey (NHANES-III) provide a clear picture of malocclusion in the US population in the 1990s. ${ }^{4}$ In this context very few studies have been conducted to assess the pattern of distribution of dental malocclusion among the population of western region of Nepal. ${ }^{5}$ The aim of this study was to determine the pattern of distribution of dental malocclusion in a sample of Nepalese orthodontic patient visiting a tertiary care center of Western Nepal.

\section{MATERIALS AND METHOD}

The sample consisted of 200 study models of patient with the age group of 8-36 years who have visited Department of Orthodontics, Universal College of Medical Sciences- 
College of Dental Surgery, Bhairahawa for orthodontic treatment. The study was conducted by evaluating the study model of the patients.

Samples having full complement of permanent teeth with the exception of third molars were included in the study. Dentitions with missing molars, any history of jaw trauma, presence of masticatory disharmony, and temporomandibular joint disorders were exclude from the study.

The study model was examined to classify into Class I, Class II and Class III malocclusion according to Angle's classification system. The classification was done using Angle's molar relationship on study models of each patient to describe the malocclusion in anterior-posterior plane and data were recorded in the data collection sheet. All the data were analyzed with SPSS software version 22.

\section{RESULT}

Out of 200 study casts examined 74 study casts were of male and 126 were of female. The ratio between male to female was 0.58:1 (Table 1). The age range in the study was 8-36 years with the mean of 18.74 years. Age groups were divided into 3 groups: 8-11 years, 12-17 years and 1836 years. Among them the age group of 18-36 (61.5\%) was the most to seek the orthodontic treatment while the age group 8-1 1 years (3\%) was the least (Table 2).

The distribution of malocclusion according to Angle's classification showed that; Class I malocclusion was most prevalent with $101(50.5 \%)$ sample followed by Class II malocclusion in $90(45 \%)$ and Class III in 9(4.5\%) (Table3). According to gender distribution, all forms of malocclusions were more prevalent in female subjects (Table 4). Among the age groups; in 8-11 and 12-17 years Class II malocclusion was the most prevalent, however in age group 18-36 the most prevalent malocclusion was Class I (Table 5).

To test the association between distribution of malocclusion and gender; Pearson chi square value was calculated. At $\propto$ value set at 0.05 and $\mathrm{df}$ of 2 , the $\mathrm{p}$-value was $0.62(\mathrm{p}<0.05)$; thus the association was nonsignificant (Table 4). However, the association between the distribution of malocclusion and age was statistically significant ( $p=0.023$ ) (Table 5).

Table 1: Gender distribution of the subjects

\begin{tabular}{|c|c|c|}
\hline Gender & Frequency & Percentage (\%) \\
\hline Male & 74 & 37 \\
\hline Female & 126 & 63 \\
\hline Total & 200 & 100 \\
\hline
\end{tabular}

Table 2: Age distribution of the subjects

\begin{tabular}{|c|c|c|}
\hline Age range & Frequency & Percentage (\%) \\
\hline $8-11$ & 6 & 3 \\
\hline $12-17$ & 71 & 35.5 \\
\hline $18-36$ & 123 & 61.5 \\
\hline Total & 200 & 100 \\
\hline
\end{tabular}

Table 3: Distribution of malocclusion according to Angle's classification

\begin{tabular}{|c|c|c|}
\hline Angle's Classification & Frequency & Percentage (\%) \\
\hline Class I & 101 & 50.5 \\
\hline Class II & 90 & 45 \\
\hline Class III & 9 & 4.5 \\
\hline Total & 200 & 100 \\
\hline
\end{tabular}

Table 4: Association of malocclusion with gender

\begin{tabular}{|c|c|c|c|c|}
\hline Angle's Classification & Male & Female & X Value & p-Value \\
\hline Class I & $33(32.67 \%)$ & $68(67.32 \%)$ & & \\
\hline Class II & $40(44.44 \%)$ & $50(55.55 \%)$ & 5.53 & 0.62 (NS) \\
\hline Class III & $1(11.11 \%)$ & $8(88.88 \%)$ & & \\
\hline Total & 74 & 126 & & \\
\hline
\end{tabular}

NS: non-significant

Table 5: Association of malocclusion with age group

\begin{tabular}{|c|c|c|c|c|c|}
\hline Age group & Class I & Class II & Class III & $X^{2}$ Value & -Value \\
\hline $8-11$ yrs & $1(16.66 \%)$ & $4(66.66 \%)$ & $1(16.66 \%)$ & & \multirow{2}{*}{$0.023^{*}$} \\
\hline $12-17 \mathrm{yrs}$ & $30(42.25 \%)$ & $35(49.29 \%)$ & $6(8.45 \%)$ & 11.27 & \\
\hline $18-36 \mathrm{yrs}$ & $70(56.91 \%)$ & $51(41.46 \%)$ & $2(1.62 \%)$ & & \\
\hline Total & 101 & 90 & 9 & & \\
\hline
\end{tabular}




\section{DISCUSSION}

The prevalence of malocclusion is found to vary with different population, racial and ethnic origin. This type of study particularly is helpful in determining and planning the type of orthodontic service that might be provided on the basis of distribution of malocclusion in a population.

Present study showed $50.5 \%$ having Angle's Class I malocclusion, $45 \%$ Class II malocclusion and $4.5 \%$ Class III malocclusion among the sample of western Nepali population. The pattern of distribution of malocclusion in the present study is similar to the study conducted by Sharma ${ }^{6}$ who found $62.28 \%$ Class I malocclusion, $29.4 \%$ Class II malocclusion and $8.2 \%$ Class III malocclusion; however the frequency of Class II malocclusion is higher in our study. Similar pattern of distribution of malocclusion had been reported by National Health and Nutrition Examination Survey (NHANES). NHANES data suggests that greatest number are Class I malocclusion (50\%-55\%), next highest group are of class $\|(15 \%)$ and the least number are of Class III (less than $1 \%$ ) and the remainder of population had normal occlusion (30\%). ${ }^{4}$ Frequency of Class II malocclusion was higher in our study as compared to the NHANES report. Since our study used the study cast of only the patient seeking orthodontic treatment none of them had normal occlusion.

According to the study conducted by Shrestha BK7 among 937 children in different schools of Kathmandu valley; normal occlusion was present in $27 \%$, Class I malocclusion in 59\% followed by Class II in $25 \%$ and Class III in $16 \%$. Another study conducted by Piya et $a^{8}$ among patient seeking orthodontic treatment in Nepal Medical College, Class I malocclusion was seen in $59.5 \%$ followed by Class II $26.7 \%$ and Class III in $13.7 \%$. The pattern of distribution of malocclusion in the present study is similar to the study conducted by Piya et al with the exception of Class III malocclusion which was higher in the later. This may be the result of ethnic variation because of higher population of mongoloids present in Kathmandu valley in comparison to Terai region of Nepal.

Another similar study was conducted by Shrestha $S$ and Shrestha RM, 9 in which the study models of 464 orthodontic patients (165 male and 299 female) of the age ranging from 11 to 30 years were studied to evaluate the prevalence of malocclusion using Angle's classification. The malocclusion status among the Nepalese seeking orthodontic treatment was $54.7 \%$ Class I, $36.9 \%$ Class II, and $8.4 \%$ Class III. Compared to this study, the present study showed similar distribution with Angle's Class I malocclusion. Nainan ${ }^{10}$ found Angle's Class I malocclusion in $49.9 \%$; which was most prevalent as compared to the other type of malocclusions. The finding is similar to the pattern and distribution of malocclusion as compared to the present study.

\section{CONCLUSION}

Based on the pretreatment records of the patients seeking orthodontic treatment in a tertiary care teaching hospital; the status of malocclusion in a sample of Western region of Nepal is:

1. The frequency of Angle's Class I, Class II and Class III malocclusion was found to be $50.5 \%, 45 \%$ and $4.5 \%$ respectively, with Class I malocclusion being the most prevalent.

2. Most of the numbers of patients seeking orthodontic treatment were female (63\%).

3. Most of the numbers of patients seeking orthodontic treatment were of the age group 18-35(61.5\%).

\section{REFERENCES}

1. Proffit WR, Fields HW, Sarver DM. Contemporary Orthodontics. 4th ed. India: Mosby, Health Science imprints of Elsevier; 2008 : 3-23.

2. Angle EH. Treatment of malocclusion of the teeth and fractures of the maxillae. In: Angle's System, Ed. 6; Philadelphia: SS White Dental Mfg Co; 1990

3. Tak M, Nagarajappa R, Sharda AJ, Asawa K, Tak A, Jalihal S. Prevalence of malocclusion and orthodontic treatment needs among 12-15 years old school children of Udaipur, India. Eur J Dent; 2013; 7:45-53.

4. Profit WR, Fields HW, Moray LJ. Prevalence of malocclusion and orthodontic treatment need in the United States: Estimates from NHANS III. Int J Adult Orthod Orthogn Surg, 1998; 13:97-106

5. Baral P. Prevalence of malocclusion in Western Nepal. Orthod J Nep, 2015; 5:2:6-8.

6. Sharma J N. Pattern of distribution of malocclusions in patients seeking orthodontic treatment at BPKIHS from Sunsari District of Nepal. Health Renaissance, 2010; 8:2:93-96.

7. Shrestha B.K, Yadav R, Basel P. Prevalence of malocclusion among high school students in Kathmandu Valley. Orthod J Nep, 2012; 2:1:1-5.

8. Piya A, Shrestha VB, Acharya J, Khanal S, Bhattarai P. Pattern of distribution of malocclusion among patients seeking orthodontic treatment at Dental College- Nepal Medical College. J Nep Dent Asso, 2013; 13:2:36-41.

9. Shrestha S, Shrestha RM. An analysis of malocclusion and occlusal characteristics in Nepalese orthodontic patients. Orthod J Nep, $2013 ; 3: 1: 19-25$.

10. Nainan O, Singh S, Mitra R, Basanar DR. Evaluation of malocclusion pattern and dentofacial characteristics in orthodontically referred urban Indians. J Ind Orthod Soc, 2013; 47:4:328-34. 